\title{
Evaluation of Anticonvulsant and Antioxidant Activity of Senna occidentalis Seeds Extracts
}

\author{
Vijay Vikram Singh ${ }^{*}$, Jainendra Jain ${ }^{1}$, Arun Kumar Mishra ${ }^{2}$ \\ ${ }^{1}$ Department of Pharmacy, Ram-Eesh Institute of Vocational and Technical Education, Greater Noida, India \\ ${ }^{2}$ Phytochemistry Laboratory, Faculty of Pharmacy, IFTM University, Moradabad, India
}

\begin{abstract}
Aim: The aim of present work was to determine the anticonvulsant and antioxidant activity of Senna occidentalis L. ethanolic seed extract by different models. Methods: For evaluation of anticonvulsant activity, Pentylenetetrazole (PTZ) seizure model and Maximal electroshock (MES) seizure model were used. For antioxidant activity, (1, 1-diphenyl - 2-picryl hydrazine (DPPH) and hydrogen peroxide $\left(\mathrm{H}_{2} \mathrm{O}_{2}\right)$ method were used. Results: The finding suggested that the ethanolic extract (EAE) of Senna occidentalis in the dose $400 \mathrm{mg} / \mathrm{kg}$ body weight posses potent anticonvulsant activity. The EAE showed anticonvulsant action in dose dependent fashion. It was observed that upon increasing the concentration of extract, it showed reduced absorbance and increased free radical inhibition, and when comparison was made with Ascorbic acid, it showed marked antioxidant property in DPPH as well as $\mathrm{H}_{2} \mathrm{O}_{2}$ method. The $\mathrm{IC}_{50}$ of Ascorbic acid and EAE by DPPH method were found to be 14.56 and 14.8 respectively whereas the $\mathrm{IC}_{50}$ of Ascorbic acid and EAE by $\mathrm{H}_{2} \mathrm{O}_{2}$ method were found that 14.3 and 14.8 respectively. Conclusion: The results of the present study concluded hat the EAE of Senna occidentalis L. possesses significant antioxidant and anticonvulsant activity. The activity was in dose dependent fashion. This study will assist in future research associated with formulation development of seeds of Senna occidentalis L.
\end{abstract}

Keyword: Senna occidentalis L., Anticonvulsant, Antioxidant, DPPH model

Article Info: Received 28 Jan 2019; Review Completed 27 Feb 2019; $\quad$ Accepted 06 March 2019; Available online 15 March 2019

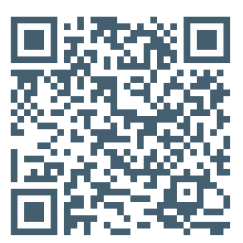

Cite this article as:

Singh VV, Jain J, Mishra AK, Evaluation of Anticonvulsant and Antioxidant Activity of Senna occidentalis Seeds Extracts, Journal of Drug Delivery and Therapeutics. 2019; 9(2):183-187 http://dx.doi.org/10.22270/jddt.v9i2.2400

*Address for Correspondence:

Vijay Vikram Singh, Department of Pharmacy, Ram-Eesh Institute of Vocational and Technical Education, Gr Noida, India

\section{INTRODUCTION}

Senna occidentalis, growing mainly in lower region, is an erect tropical annual herb. The seed are dark brown and curved with slightly upward, the seeds are brown and flattened on both ends. The seeds, in the long pods, can be roasted and made into a coffee like drink ${ }^{1}$. Senna occidentalis is known by various names, e.g. Coffee Senna, Fedegoso and Negro coffee. It is common weed scattered from Himalayas to the Western Bengal, South India, Burma and Ceylon. The main phytoconstituents present in Senna occidentalis L. includes aloe emodin, anthraquinones, anthrones, apigenin, aurantiobtusin, campesterol, cassiollin, chrysophanol, chrysoeriol, cmodin, physicon quarcetin, rhamnosides, rhein, sitosterols, and xanthorine etc ${ }^{2}$. The plant is bitter in taste, thermogenic, purgative, expectorant, antipyretic and anticonvulsants as it is used by tribals to treat such problems.

Senna occidentalis is reported to have number of medicinal properties in Ayurveda. Senna occidentalis is used in traditional system of medicine as antipyretic and to treat convulsions in Andhra Pradesh, India with very popularity ISSN: 2250-1177 but still its pharmacological potential for antioxidant activity and other activities including anticonvulsant has not been fully explored. In present work, with scientific model are used to prove the claim of this drug. The traditional treatise of Ayurveda states the claim of this important drug as antiepileptic (Aakeshpa treatment) and health supplement. Since thousands of year ago, it is used to treat pyrexia and inflammation by tribals.

The literature review revealed that the potential of Senna occidentalis as anticonvulsant and antioxidant drug still to be experimentally proven. The present investigation includes pharmacological evaluation of Senna occidentalis ethanolic seed extract.

\section{MATERIALS AND METHODS}

\section{Collection and identification of plant material}

The seeds of Senna occidentalis belonging to the family Fabaceae were cultivated and collected from the Herbal garden area of Ram-Eesh Institute of Vocational and Technical Education, Greater Noida, District Gautam Budhdha Nagar, U.P., India. 


\section{Identification}

The plant and the seeds of Senna occidentalis were identified and authenticated by Dr. Sunita Garg, Chief Scientist, National Institute of Science Communication and Information Resources (NISCAIR), New Delhi.

\section{Preparation of the extract}

The seeds of Senna occidentalis were shade dried and reduced to the coarse powder. The coarse powder $(1 \mathrm{Kg})$ was evenly packed in the Soxhlet apparatus, was subjected to defating ${ }^{3}$. The powdered seeds were defatted by petroleum ether $\left(60-80^{\circ} \mathrm{C}\right)$ until the color has been changed from dark yellow to colorless. The marc was subjected to the extraction in the presence of ethanol as extraction solvent. The ethanolic extract (EAE) was filtered and filtrate was concentrated by rotary evaporator. The EAE in different concentration was subjected to evaluation of anticonvulsant activity by Pentylenetetrazole (PTZ) seizure model and Maximal electroshock (MES) seizure model. For antioxidant activity evaluation of EAE, (1, 1-diphenyl - 2-picryl hydrazine (DPPH) and hydrogen peroxide $\left(\mathrm{H}_{2} \mathrm{O}_{2}\right)$ method were used

\section{Experimental animals}

For anticonvulsant activity using PTZ model, Swiss albino mice (approximately weighing 30-40 g) and for MES model, Swiss Albino rats of either sex (approximately weighing 200$250 \mathrm{~g}$ ) were used. The animals for the activity were procured from Institutional Animal House, Department of Pharmacy, Ram-Eesh Institute of Vocational and Technical Education, Greater Noida. All the laboratory animals were kept in temperature controlled room conditions, with $12 \mathrm{~h}$ alternating light and dark cycle. The animals were given adequate nutrition and water ad libitam. The protocols were followed as per "Guidelines for the Care and Use of Laboratory Animals" and approved by the Institutional Animal Ethics Committee (IEAC) (Ref. Number, RGI/RIT/01/2016; dated 16.01.2016)

\section{Experimental design}

Anticonvulsant Activity

Pentylenetetrazole (PTZ) induced seizure test $\mathrm{t}^{4,5}$

The swiss albino mice were randomly divided into 05 groups having six $(n=6)$ animals in each groups. The animals were divided into all five groups as follows-

Group I : $\quad$ (Negative Control): Treated with normal saline $(10 \mathrm{ml} / \mathrm{kg}) \mathrm{b} . \mathrm{w}$

Group II : $\quad$ (Positive Control): Treated with Valproic acid $(300 \mathrm{mg} / \mathrm{kg})$ b.w

Group III : $\quad$ (Test Group): Treated with EAE (100 mg/ kg) b.w

Group IV : (Test Group): Treated with EAE (200 mg/ kg) b.w

Group V : $\quad$ (Test Group): Treated with EAE (400 mg/ $\mathrm{kg}$ ) b.w

The mice were given the treatment of extract and normal saline to control groups (i.p.), $30 \mathrm{~m}$ prior to the administration of $25 \mathrm{mg} / \mathrm{kg}$ b.w (PTZ). The animals were placed individually in plastic boxes and observed immediately after PTZ injection for a period of $30 \mathrm{~m}$ and after $24 \mathrm{~h}$. The onset time of hind limb tonic extensions (HLTEs) and the ratio of convulsion survivors to total animals tested (mortality protection) were recorded (Table 1; Figure 1, 2)
Maximal Electroshock Induced Seizures (MES) Model6,7

In order to procure tonic convulsion in Albino rats, crocodile ear clip were used and through this, $150 \mathrm{~mA}$ current maximum for $0.2 \mathrm{~S}$ was discharged through electroconvulsiometer (Inco, Ambala). The electric shock was given just after administration of either vehicle (normal saline $10 \mathrm{ml} / \mathrm{kg} \mathrm{b.w}$ ) or test drug (EAE in dose of 100, 200 and $400 \mathrm{mg} / \mathrm{kg} \mathrm{b.w)}$ and after $90 \mathrm{~m}$ of standard drug i.e. Valproic acid $300 \mathrm{mg} / \mathrm{kg}$ p.o.)

The number of animals protected from tonic hind limb extension (HLTE) indicates the abolition of tonic hind limb extension within $10 \mathrm{~S}$ after delivery of the electroshock and the duration of observed, HLTE was recorded for each group. For measurement of this, rats were placed in clear rectangular plastic cages with an open top, permitting full view of the animal's motor responses to seizure. The parameters selected for present study were tonic flexion, extension, clonus, stupor and mortality. The findings are presented in table 2 and Figure 3,4. The albino rats were randomly divided into 5 groups of $n=6$ as follows-

Group I: (Negative Control): Treated with normal saline (10 $\mathrm{ml} / \mathrm{kg}$ ) b.w

Group II: (Positive Control): Treated with Valproic acid (300 $\mathrm{mg} / \mathrm{kg}$ ) b.w

Group III : (Test Group): Treated with EAE (100 mg/ kg) b.w Group IV : (Test Group): Treated with EAE (200 mg/ kg) b.w Group V: (Test Group): Treated with EAE (400 mg/ kg) b.w Antioxidant Activity

Free radical scavenging activity of Senna occidentalis L by DPPH Method 8,9

Different conc. $(10 \mu \mathrm{l}-50 \mu \mathrm{l})$ of EAE sample and standard sample were prepared. To this, $3 \mathrm{ml}$ of a $0.004 \%(\mathrm{w} / \mathrm{v})$ solution of DPPH in methanol was added in each test tube. The reaction mixtures were shacked and then incubated at room temperature for period of $30 \mathrm{~m}$. A blank was prepared in similar way, without DPPH and absorbance was measured at $517 \mathrm{~nm}$ using double beam UV-Visible spectrophotometer (Shimadzu 1800). Free radical scavenging activity was expressed as the percentage inhibition calculated using formula -

Percentage Inhibition DPPH scavenging effect (\%) =

$\frac{\text { Absorbance of control sample (Ao) - Absorbance of test sample) (A1) }}{\text { Absorbance of control sample (Ao) }} \times 100$

$A_{0}$ was absorption of control reaction and $A_{1}$ was absorption in presence of test or standard sample. Ascorbic acid was used as a positive control. IC 50 value was calculated from $\%$ inhibition. The $\mathrm{IC}_{50}$ value of the sample, which is the concentration of sample required to inhibit $50 \%$ of the DPPH free radical, was calculated using inhibition curve. Lower absorbance of reaction mixture indicates higher free radical activity (Table 3,4).

Free radical scavenging activity of Senna occidentalis $L$ by Hydrogen peroxide method ${ }^{10,11}$

$1 \mathrm{ml}$ of $10 \%(\mathrm{v} / \mathrm{v}$ ) sample / standard solution Ascorbic Acid $(10-50 \mu \mathrm{g} / \mathrm{ml})$ was added to the $0.6 \mathrm{ml}$ of the hydrogen peroxide solution which is prepared in phosphate buffer $\mathrm{pH}$ - 7.4). The sample solutions were incubated for $10 \mathrm{~m}$ at 370 C. Hydrogen peroxide in phosphate buffer solution it was used as control. Absorbance was measured at $230 \mathrm{~nm}$ (Ebrahizadeh et al., 2010). The formula employed for \% inhibition was as follows- 


\section{RESULTS AND DISCUSSION}

Percentage Inhibition (\%) =

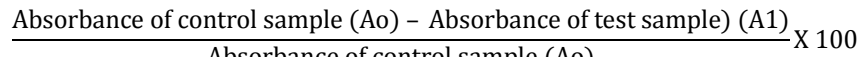
Absorbance of control sample (Ao)

\section{Anticonvulsant Activity}

Pentylenetetrazole-induced seizure test

A0 was absorption of control reaction and $A_{1}$ was absorption in presence of test or standard sample (Table 5,6)

Table 1: Effect of Senna occidentalis on Anticonvulsant effect ( PTZ model)

\begin{tabular}{|l|l|l|l|c|}
\hline Treatment & \multicolumn{1}{|c|}{ Dose (mg/kg) } & \multicolumn{1}{|c|}{$\begin{array}{c}\text { Onset of Tonic } \\
\text { Convulsions }\end{array}$} & $\begin{array}{c}\text { Onset of Clonic } \\
\text { Convulsions }\end{array}$ & Survived/Used \\
\hline Group I & Control & $75.24 \pm 1.62$ & $150.27 \pm 2.45$ & $5 / 6$ \\
\hline Group II & Valproic Acid 300 & $935.0 \pm 2.31^{* * *}$ & $1556 \pm 2.23^{* * *}$ & $6 / 6$ \\
\hline Group III & EAE 100 & $507.21 \pm 2.14^{* *}$ & $1254.0 \pm 3.64^{*}$ & $6 / 6$ \\
\hline Group IV & EAE 200 & $753.32 \pm 2.54^{* * *}$ & $1398.21 \pm 2.31^{* *}$ & $6 / 6$ \\
\hline Group V & EAE 400 & $912.12 \pm 1.4^{* * *}$ & $1498.5 \pm 2.15^{* * *}$ & $6 / 6$ \\
\hline
\end{tabular}

Values are expressed in mean \pm SEM are represent various phases of convulsion in seconds. Significant at $\mathrm{P}<0.001^{* * *}$ and $\mathrm{P}<0.01^{* *}$, compared with the control group.

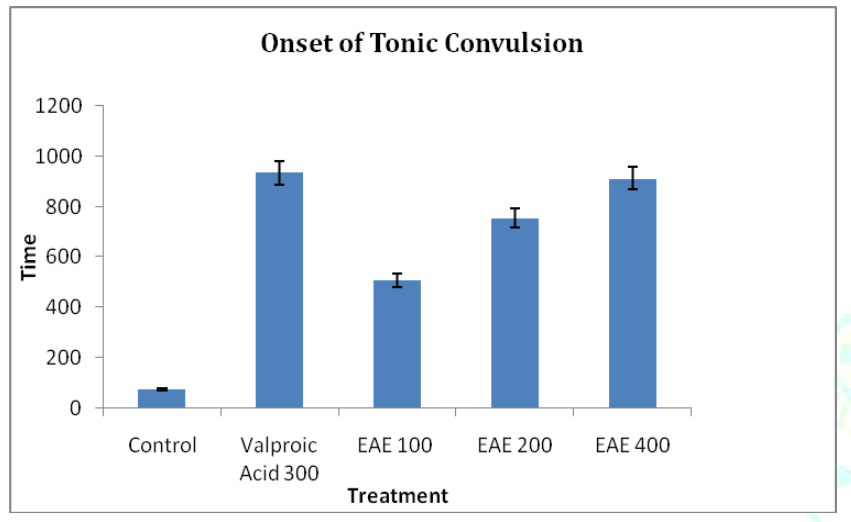

Figure 1: Effect of Senna occidentalis on onset of tonic convulsions

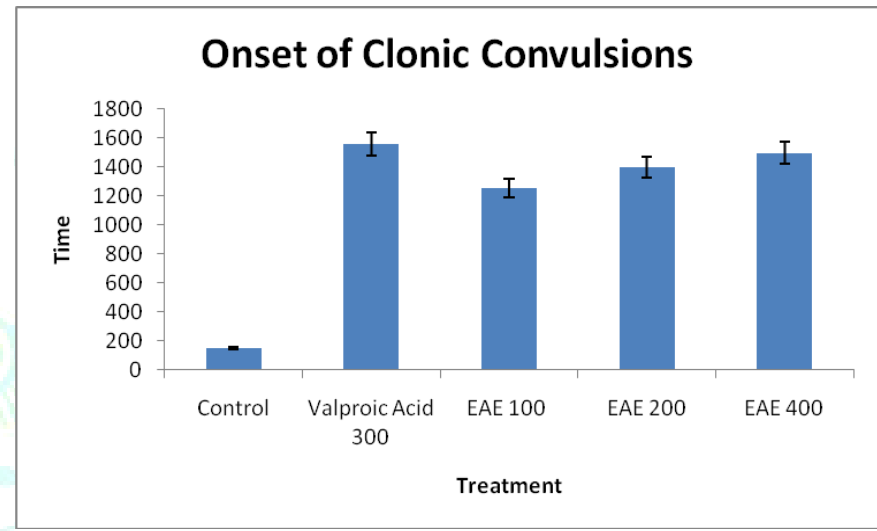

Figure 2: Effect of Senna occidentalis on onset of clonic convulsions

Maximal Electro Shock Induced seizures (MES)

Table 2: Effect of Senna occidentalis on Maximum electroshock induced seizures

\begin{tabular}{|l|l|l|l|l|l|l|}
\hline \multicolumn{1}{|c|}{ Treatment } & \multicolumn{1}{|c|}{ Dose (mg/kg) } & \multicolumn{1}{|c|}{ Flexon } & \multicolumn{1}{|c|}{ Extensor } & \multicolumn{1}{|c|}{ Clonus } & \multicolumn{1}{|c|}{ Stupor } & survived/used \\
\hline Group I & Control & $15.98 \pm 0.16$ & $13.72 \pm 0.94$ & $14.67 \pm 0.91$ & $9.27 \pm 0.94$ & $0 / 6$ \\
\hline Group II & Val Acid 300 & $3.18 \pm 0.51^{* * *}$ & $1.12 \pm 0.01^{* * *}$ & $3.21 \pm 0.07^{* * *}$ & $1.19 \pm 0.01^{* * *}$ & $6 / 6$ \\
\hline Group III & EAE 100 & $8.14 \pm 0.09$ & $4.08 \pm 0.11^{* *}$ & $10.14 \pm 0.51^{* *}$ & $6.27 \pm 0.05$ & $6 / 6$ \\
\hline Group IV & EAE 200 & $6.26 \pm 0.03^{* *}$ & $2.92 \pm 0.03^{* * *}$ & $6.24 \pm 0.65^{* * *}$ & $3.42 \pm 0.07^{* * *}$ & $6 / 6$ \\
\hline Group V & EAE 400 & $4.18 \pm 0.06^{* * *}$ & $2.02 \pm 0.06^{* * *}$ & $3.92 \pm 0.98^{* * *}$ & $1.84 \pm 0.04^{* * *}$ & $6 / 6$ \\
\hline
\end{tabular}

Values are expressed in mean \pm SEM are represent various phases of convulsion in seconds. Significant at $\mathrm{P}<0.001^{* * *}$ and $\mathrm{P}<0.01^{* *}$, compared with the control group.

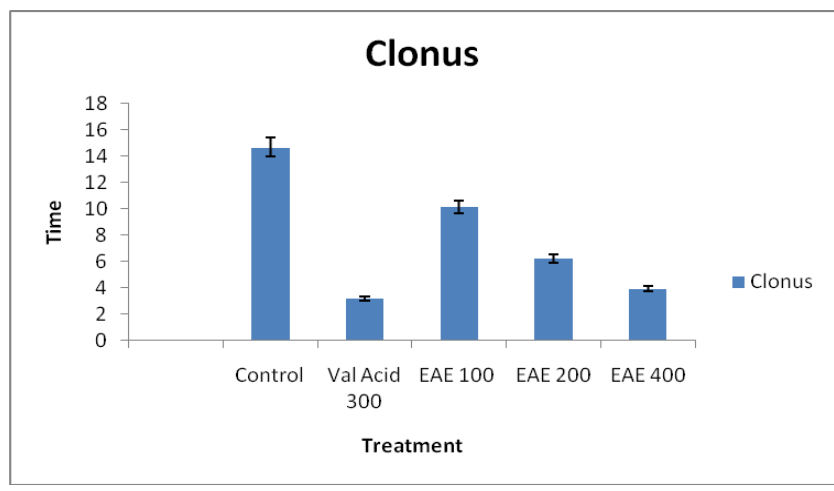

Figure 3: Effect of Senna occidentalis on MES induced seizures
The findings suggested that the EAE was effective against seizures. Upon comparision of all dose level, it was observed that EAE $(400 \mathrm{mg} / \mathrm{kg})$ b.w was most effective among all the dose level. The activity was observed in dose dependent manner. The results of this study demonstrated that the ethanolic extract have anticonvulsant activity. Data showed that the ethanolic extract displayed anticonvulsant effect in the PTZ induced seizure model. In the MES test, the ethanolic extract reduced the duration of HLTE. According to the data, the extract exhibited protective effects against mortality in MES experiments. 


\section{Antioxidant Activity}

Free radical scavenging activity of Senna occidentalis L by DPPH.

Polyphenolic compounds present in plant contribute significantly to the total antioxidant capacity of the seeds. Flavonoids play some important pharmacological roles against diseases, such as cardiovascular diseases, cancer, inflammation and allergy. In the present study, reduction of the DPPH radicals was found in concentration dependent manner. The Senna occidentalis ethanolic extract reduced the stable DPPH radical to yellow colored unstable compound. However, ascorbic acid displays significant scavenging activity over the Senna occidentalis ethanolic extract. This might to due to the presence of flavanoid content which increases the quenching the free radical. The absorbance was measured using spectrophotometer and the same is presented in Table 3. The findings of \% inhibitions of free radicals are presented table 4 .

Table 3: In-vitro Antioxidant effect of extracts of Senna occidentalis L. seeds (by DPPH method)

\begin{tabular}{|c|c|c|c|}
\hline Sl. No & $\begin{array}{c}\text { Concentration } \\
\boldsymbol{\mu g} / \mathbf{m l}\end{array}$ & \multicolumn{2}{|c|}{ Absorbance } \\
\cline { 3 - 4 } & 10 & $0.3254 \pm 0.001$ & $0.2645 \pm 0.004$ \\
\hline 1 & 20 & $0.1917 \pm 0.002$ & $0.2314 \pm 0.005$ \\
\hline 2 & 30 & $0.1012 \pm 0.001$ & $0.1874 \pm 0.003$ \\
\hline 3 & 40 & $0.0742 \pm 0.001$ & $0.1542 \pm 0.012$ \\
\hline 4 & 50 & $0.0654 \pm 0.002$ & $0.0874 \pm 0.011$ \\
\hline 5 & \multicolumn{2}{|c}{} \\
\hline
\end{tabular}

Table 4: Percentage of Inhibition of EAE with Ascorbic acid

\begin{tabular}{|c|c|c|}
\hline Concentration $(\boldsymbol{\mu g} / \mathbf{m l})$ & Ascorbic Acid (\%) & EAE (\%) \\
\hline 10 & 22.76 & 41.82 \\
\hline 20 & 54.49 & 51.2 \\
\hline 30 & 75.97 & 63.39 \\
\hline 40 & 82.38 & 68.02 \\
\hline 50 & 84.8 & 79.25 \\
\hline
\end{tabular}

\section{Free radical scavenging activity of Senna occidentalis by $\mathrm{H}_{2} \mathrm{O}_{2}$ method}

$\mathrm{H}_{2} \mathrm{O}_{2}$ is highly important because of its ability to penetrate biological membranes. $\mathrm{H}_{2} \mathrm{O}_{2}$ itself is not very reactive, but it can sometimes be toxic to cell as it may give rise to hydroxyl radical in the cells. The different fractions of ethanol extract are tested for hydrogen peroxide scavenging activity. The results showed that extracts of Senna occidentalis had an effective $\mathrm{H}_{2} \mathrm{O}_{2}$ scavenging activity. The highest inhibition of free radical was recorded for $50 \mu \mathrm{g} / \mathrm{ml}$ concentration of EAE where as least free radical scavenging was observed for 10 $\mu \mathrm{g} / \mathrm{ml}$ concentration of EAE. The inhibition of free radical was recorded in dose dependent manner. The absorbance was measured using spectrophotometer and the same is presented in Table 5.

Table 5: In-vitro Antioxidant effect of extract of Senna occidentalis seeds (by $\mathrm{H}_{2} \mathrm{O}_{2}$ method)

\begin{tabular}{|c|l|l|}
\hline $\begin{array}{c}\text { Concentration } \\
\boldsymbol{\mu g} / \mathbf{m l}\end{array}$ & \multicolumn{2}{|c|}{ Absorbance } \\
\cline { 2 - 3 } & Ascorbic Acid & EAE \\
\hline 10 & $0.2145 \pm 0.005$ & $0.2421 \pm 0.002$ \\
\hline 20 & $0.1984 \pm 0.004$ & $0.2032 \pm 0.004$ \\
\hline 30 & $0.1645 \pm 0.008$ & $0.1874 \pm 0.003$ \\
\hline 40 & $0.1121 \pm 0.010$ & $0.1745 \pm 0.011$ \\
\hline 50 & $0.0765 \pm 0.007$ & $0.1654 \pm 0.004$ \\
\hline
\end{tabular}

Table 6: Percentage of Inhibition of PEE, EAE and AEE with Ascorbic acid

\begin{tabular}{|l|l|l|}
\hline Concentration $\boldsymbol{\mu g} / \mathbf{m l}$ & Ascorbic Acid & EAE (\%) \\
\hline 10 & 18.21 & 24.23 \\
\hline 20 & 52.01 & 54.28 \\
\hline 30 & 73.21 & 66.21 \\
\hline 40 & 81.20 & 69.02 \\
\hline 50 & 84.22 & 74.25 \\
\hline
\end{tabular}

ISSN: 2250-1177
The \% inhibition was recorded for dilution of extracts (10-50 $\mu \mathrm{g} / \mathrm{ml}$ ), using Ascorbic acid as standard and the findings are presented table 6 .

The finding suggested that the EAE of Senna occidentalis posses potent activity of anticonvulsant. The EAE showed anticonvulsant action in dose dependent fashion. The EAE showed less anticonvulsant activity when it was given 100 $\mathrm{mg} / \mathrm{kg}$ body weight but the effect was increased when dose increased. The maximum anticonvulsant effect was found when the dose was given in $400 \mathrm{mg} / \mathrm{kg}$ body weight in PTZ induced seizure. The effect was increased when dose was high. When all the three dose levels of EAE were compared with positive control, it was seen that the EAE $(400 \mathrm{mg} / \mathrm{kg}$ bw.) was most effective extract.

The EAE showed anticonvulsant property in MES induced model in dose dependent fashion. The effect was highest when the dose was given $400 \mathrm{mg} / \mathrm{kg}$ and the effect was lowest when the dose was $100 \mathrm{mg} / \mathrm{kg}$ b.w. When all the three dose levels of EAE extracts were compared with control group, it was found that the EAE (400mg/kg bw) is having significant anticonvulsant property.

The findings suggested that the EAE possessed a potent antioxidant property. It was seen that as the concentration of the extract as increases, the extract showed decrease of absorbance and in comparison with Ascorbic acid, it showed marked antioxidant property in DPPH as well as Hydrogen peroxide model. The $\mathrm{IC}_{50}$ is the half maximal inhibitory concentration 12,13 . The IC 50 of Ascorbic acid and EAE in DPPH method were found that 14.56 and 14.8 respectively. The $\mathrm{IC}_{50}$ of Ascorbic acid and EAE in Hydrogen peroxide model were found that 14.3 and 14.8 respectively. It was seen that, as the extract concentration increases, the absorbance decreases. The result of antioxidant activity using both models suggested that $50 \mu \mathrm{g} / \mathrm{ml}$ concentration of EAE was most potent in exhibiting the antioxidant response when comparison was made with Ascorbic acid. 


\section{CONCLUSION}

The research conducted on assessment of anticonvulsant and antioxidant profile of Senna occidentalis extracts revealed that EAE in $400 \mathrm{mg} / \mathrm{kg}$ b.w. exhibits most potent anticonvulsant response when evaluation was done on MES and PTZ induced model. Similarly, the $50 \mu \mathrm{g} / \mathrm{ml}$ dilution of EAE showed maximum response in Antioxidant activity in both the models viz DPPH model and Hydrogen peroxide model.

\section{ACKNOWLEDGEMENT}

The authors are thankful to Management, Ram-Eesh Institute of Vocational and Technical Education, Greater Noida (U.P.) for assistance towards this research work. The present work is a part of Ph.D from IFTM University, Moradabad.

\section{CONFLICT OF INTEREST}

The authors have no conflict of interest.

\section{REFERENCES}

1. The Wealth of India. A dictionary of Indian Raw Material and Industrial Products. New Delhi: Council of Scientific and Industrial Research, 1998; pp. 350.

2. Sini KR, Sinha BN, Karpakavalli M, Sangeetha PT. Analgesic and antipyretic activity of Senna occidentalis Linn. Annals of Biological Research. 2011; 2 (1):195-200.

3. Hong N, Van TN, Quan VV. Effect of Extraction Solvents and Drying Methods on the Physicochemical and Antioxidant Properties of Helicteres hirsuta Lour. Leaves. 2015; 3:285-301

4. Shyamjith M, Deepa B, Anu E Joy and Rao S N. Anticonvulsant Activity of Phyllanthus Amarusin Experimentalanimal Models. International Journal of Applied Biology and Pharmaceutical Technology. 2011; 2(4):144-149.
5. Joshi R, Reeta KH, Sharma SK, Tripathi M, Gupta YK. Pharmacodynamic and pharmacokinetic interaction of Panchagavya Ghrita with phenytoin and carbamazepine in maximal electroshock induced seizures in rats. Ayu. 2015; 36: 196-202.

6. Chauhan A.K, Dobhal M.P, Joshi B.C., A review of medicinal plants showing anticonvulsant activity, Journal of Ethnopharmacology, 1988, 22:11-23.

7. McNamara J0., Drugs effective in the therapy of the epilepsies: In: Goodman and Gillman's "The pharmacological basis of therapeutics", McGraw-Hill, New York, 2001, 521-539.

8. Pandey MM, Vijayakumar M, Rastogi S, Rawat AKS. Phenolic content and antioxidant properties of selected Indian spices of Apiaceae. J Herb, Spice Med Plant 2012; 18:246-56.

9. Ebrahimzadeh AM, Nabavi SM, Nabavi SF, Bahramiyan F, Bekhradni AR. Antioxidant and Free Radical Scavenging Activity of H. Officinalis L. angustifolius, V. odorata, B. hyrcana and C. speciosum. Pakistan Journal of Pharmaceutical Science.2010; 23(1):29-34.

10. Furuta, S., I. Suda, Y. Nishiba and O. Yamakaw. High tertbutylperoxy radic al scavenging activities of sweet potato cultivars with purple flesh. Food Sci., Technol. 1998; 4:33-35.

11. Zahin M, Aqil F, Ahmad I. Broad spectrum antimutagenic activity of antioxidant active fraction of Punica granatum L. peel extracts. Mutat Res. 2010; 703:99-107.

12. Zidane H, Elmiz M, Aouinti F, Tahani A, Wathelet J, Sindic M, Elbachiri A. Chemical composition and antioxidant activity of essential oil, various organic extracts of Cistus ladanifer and Cistus libanotis growing in Eastern Morocco. African J. of Biotechnology, 2013; 34(12): 5314-5320.

13. Tepe B., Sokmen M., Akpulat H.A., Sokmen A. Screening of the antioxidant potentials of six Salvia species from Turkey. Food Chem.2006; 95:200-204

14. Jain $\mathrm{S}$. The role of epilepsy management guidelines in a developing country. Neurology Asia 2011; 16:57-8 